\title{
Social and Racial Justice as Fundamental Goals for the Field of Human Development
}

\author{
Melanie Killen ${ }^{a}$ Kathryn M. Yee ${ }^{a}$ Martin D. Ruck ${ }^{b}$ \\ ${ }^{a}$ Department of Human Development and Quantitative Methodology, University of Maryland, College Park, MD, \\ USA; ${ }^{b}$ City University of New York Graduate Center, New York, NY, USA
}

\section{Keywords}

Development · Social justice $\cdot$ Racism $\cdot$ Ethnicity $\cdot$ Prejudice $\cdot$ Lay theories

\begin{abstract}
Social justice refers to promoting fairness, equality, equity, and rights across multiple aspects of society, including economic, educational, and workforce opportunities. A number of scholars across academia have called for a greater incorporation of social and racial justice approaches to the field of human development and have asserted that social justice constitutes both a theoretical framework as well as a set of hypotheses to investigate and understand the human condition. The emergence, experience, and awareness of social injustice needs to be better understood from a psychological and developmental perspective. Four areas that reflect theoretical changes in human development research are featured in this issue: (a) socialization theories about race; (b) ethnic/racial identity and development; (c) developmental social identity and moral reasoning; and (d) lay theories and social essentialism. Childhood is a period of intense change and development. Human development research is uniquely positioned to promote change that will contribute to challenging social and racial injustice.

(c) 2021 S. Karger AG, Basel
\end{abstract}

\section{Social and Racial Justice as Fundamental Goals for the Field of Human Development}

Throughout human history, individuals have fought for justice, fairness, and equality, most often in the context of overwhelming competing factors. The formation of social hierarchies and cultural institutions has enabled societies to produce achievements reflecting human ingenuity, creativity, and technological innovation. However, these achievements have also reflected the development of power structures, designed to enable only a small portion of the population to enjoy many of societies' accomplishments. Systemic efforts to thwart individual freedom, autonomy, and integrity, and worse, to denigrate and exclude others, have resulted in large sections of society in positions of servitude to those who are reaping the benefits of their labor. Relationships between the individual and the group are a constant dynamic, and one that must be better understood in order to make progress towards social justice.

Social justice is closely tied to human rights and refers to promoting fairness, equality, and equity across multiple aspects of society, including economic, educational, and workforce opportunities (Bonilla-Silva, 1997; Jost \& Kay, 2010; Kendi, 2016; Petersen et al., 2016; Ruck et al., 
2014; Turiel et al., 2016). Ethical and political philosophers (along with legal scholars) often consider social justice to be more difficult to precisely define compared to other moral concepts (Anderson, 1999; Appiah, 2005; Fourie et al., 2015; Jost \& Kay, 2010; Rawls, 1971). This is due to the difficulty of ensuring that the obligatory core principles of respecting human dignity are identified and executed. What principles provide the most fair and equitable outcome? From many perspectives, social justice is associated with political movements that strongly advocate for expanding access to social and economic opportunities.

A number of scholars across academia have called for a greater focus on social justice, and specifically racial justice as a fundamental aspect of research on human development. Further, it has been asserted that social and racial justice constitutes both a theoretical framework as well as a set of hypotheses to investigate and understand the human condition (Anderson, 1999; Kendi, 2016; Killen \& Dahl, 2021; Turiel et al., 2016). In order to identify the core principles necessary for ensuring human dignity, the emergence, experience, and awareness of social inequalities and injustice has to be explicitly acknowledged. This is particularly important for those working within a psychological perspective, given the gross inaccuracies in how racial, ethnic, and gender data have been collected, interpreted, and understood in psychology and the social sciences. As will be discussed below, these inequalities include sample selection, inaccuracies regarding techniques for measuring psychological capacities such as cognitive, moral, emotional, and biological competencies as well as politically motivated analyses and interpretations of data. By politically motivated interpretations, we refer to instances in which findings about human capacities are generated and interpreted to promote power hierarchies, maintain the status quo, and assert limits on social mobility.

Further, childhood and adolescence are times of profound change and development. Studying human development during these periods of change provides a window into how beliefs, concepts, attitudes, and behaviors emerge. Examining developmental emergence provides a roadmap for how to intervene effectively in childhood to enable children and adolescents to become resilient to discrimination and its deleterious effects, and to promote an orientation towards rectifying, challenging, and resisting unfair treatment towards others.

The urgent attention to racial injustice has stemmed from political movements that have called attention to societal conflict around the globe rising from a long history of racism (Clark \& Clark, 1947; Graves, 2002; Kendi,
2016, 2019; Khan-Cullors \& Bandele, 2018; King, 1986), the lack of adequate representation of ethnic and racial minority viewpoints within psychological research conducted in North America and much of Europe (Brown et al., 2019; Graham et al., 2009; Nishina \& Witkow, 2020; Roberts \& Rizzo, 2020) and the lack of an explicit focus on social justice as a fundamental field of inquiry in psychological research (Jost \& Kay, 2010; Killen et al., 2011; Turiel et al., 2016).

While the principles of social justice have existed in theories and scholarship in psychological research, voices for social justice have been consistently undermined by research designed to reject the basic premise that individuals are equal, deserve fundamental rights, and that individuals experience discrimination. Thus, the revitalized call for social justice as a research topic in human development challenges a long history of research which has challenged and resisted the premise that humans are created equal, deserve to be treated fairly, and are due a set of rights regarding life and liberty.

As examples, scholars have argued against efforts to undermine social justice approaches from fields outside of psychological theories, including biology (Gould, 1981; Graves, 2002), sociology, and philosophy (Anderson, 1999; Appiah, 2001; Nussbaum, 1999; Sen, 2009), as well as within psychology, as we discuss below. Gould (1981), an evolutionary biologist, demonstrated how racist notions about intelligence were perpetrated by scientific studies during the 19th century. He critiqued the statistical methods underlying biological determinism, the belief that differences between groups based on race, gender, and socioeconomic status, were inborn distinctions. Graves (2002), an evolutionary biologist, thoroughly reviewed the history of concepts about race from antiquity through social Darwinism as well as current research on the biological basis of race and has effectively argued against the notion of a biological basis for race. Philosophers like Anderson (1999), Appiah (2001), and Nussbaum (1999) have written about the necessity of revising philosophical theories to consider both social equalities and inequalities, the ethics of identity, and the role that social hierarchies play regarding the denial of rights.

Psychological research is rife with examples of research that was conducted to promote the view that the color of one's skin was related to intelligence (Herrnstein, 1994; Jensen, 1998; for a critique, see Gould, 1981), that women were morally inferior (for critiques, see Deaux \& Major, 1987; Saini, 2017), that gender and sexual orientation are biologically determined, fixed and immutable (for a critique, see Horn \& Sinno, 2014), and that non- 
White indigenous cultures were inferior to European White cultures (for a critique, see Deaux, 2006). These are only a subset of the categories of people that have been denigrated and denied basic freedoms and serve to point out that psychological research in the past has explicitly worked against the promotion of social justice. These efforts were effective partly because they used scientific data to substantiate erroneous claims about the capacities of individuals based on their group identity, as well as to promote the notion that humans can be divided into different "sub-species," with some innately inferior to others (e.g., by skin color, gender, or geography; for a critique see Graves, 2002).

Turiel et al. (2016) have argued that psychological research perspectives that have characterized individuals as nonrational or irrational lead to the erroneous assumption that human decision-making about unfair and unequal practices is trivial or non-substantive. As an example, among other non-cognitive theories, social intuitionism has promoted the viewpoint that individuals' responses to moral violations and mistreatment of others are not motivated by rationality or reason but from an emotive "gut" response (Haidt \& Bjorklund, 2008). This approach has served to undermine or dismiss genuine efforts by individuals to point out inequalities and demonstrate psychological data in which individuals provide explanations for what makes acts towards others wrong from a fairness and equity position.

In fact, extensive research demonstrates that from childhood to adulthood, individuals are capable of critically evaluating social systems and resisting unfair practices (Elenbaas et al., 2020; Hughes et al., 2006; Killen \& Dahl, 2021; Ruck et al., 2014; Turiel, 2002). Judgments about the wrongfulness of societal traditions that exclude groups based on gender, race, and ethnicity are not "irrational," but, in fact, rational inferences about how individuals ought to treat one another (Appiah, 2001; Nussbaum, 2001; Sen, 2009).

Further, conceptualizations of the role of the larger societal and cultural context in the development of psychological attitudes and thinking about social justice have undergone substantial changes. In the past, scholars have proposed that justicewas a Western concept, reflective of individuals living in modern, not traditional cultural contexts (Shweder et al., 1987). The argument was that the psychological orientations of individuals living in traditionally hierarchical societies were duty-bound and authority-oriented, in contrast to individuals living in modern societies, who were oriented toward fairness, justice, and autonomy (Shweder et al., 1987; Triandis,
1995). These frameworks aimed to broaden the scope of psychology to include non-Western cultures but ultimately resulted in an overly binary view of individuals in cultures and ignored non-Western individuals' capacity to reason about or be concerned with autonomy, freedom, rights, and individuality (Oyserman et al., 2002; Raeff, 2010).

Whereas past research characterized individuals' orientations towards fairness and justice as tied to one's national or cultural identity, recent research has demonstrated that individuals from rural and urban, "Western and non-Western," traditional and modern, wealthy and poor backgrounds care about social justice, fairness, equality, and rights. Several events changed these characterizations and showed that individuals across societies have an orientation towards justice. First, communication and migration across the global world increased, expanding the heterogeneity of values and perspectives within cultures and countries. These changes motivated researchers to include many more minority perspectives in their research methodologies and to formulate new questions to address the broad variety of experiences, judgments, and behavior. The result has been a recognition that cultures are not monolithic, nor do cultural ideologies fully determine how individuals think, believe, evaluate, or act (Helwig, et al., 2014; Verkuyten, 2014; Wainryb \& Recchia, 2014). Even within authoritarian cultures, individuals resist and challenge social hierarchies, albeit with a greater recognition of the costs than for those who live in cultures with more individual freedoms (Turiel, 2002). In fact, across most cultural contexts, individuals value personal autonomy; as well, individuals care about family coherence, group functioning, and group loyalty.

Second, the inclusion of Australia and New Zealand as Western despite being in the Eastern and Southern hemispheres contributed to the recognition that "Western" is a referent for countries colonized by White Europeans, relegating non-White Europeans to sharing a psychological orientation as authority- and duty-bound rather than one considering issues of justice and fairness (Sen, 2009). This hidden meaning of the term "Western," along with the within-culture diversity of values, beliefs, and attitudes has moved the field away from the false dichotomy of Western versus non-Western. Moreover, many countries in the Western hemisphere are ethnically and racially diverse, creating a number of inconsistencies at best, or egregious assumptions at worse, of cultural homogeneity of values and psychological attitudes within these contexts. 
Third, research on individual orientations has shown that psychological values do not necessarily mirror cultural ideologies. Individuals living in various cultural contexts both accept and reject cultural norms and values (Killen et al., 2015; Turiel, 2002). As psychological research and, more specifically, developmental psychological data have expanded to consider the experiences of those beyond White European heritage, the data have revealed that different individuals challenge cultural ideologies, even when the cost is high. As examples, several decades of research have demonstrated that children in a wide range of cultures accept and reject parental norms (Smetana, 2011), give priority to the group in some contexts and to the individual in other contexts (Gönültaş \& Mulvey, 2019), assert their own agency (Grütter et al., in press), and are critical of societal and governmental policies and laws that restrict individuals' freedoms and rights as well as demonstrate compliance (Helwig et al., 2014; Ruck et al., 2019).

Further, recent events across the globe have shown individuals (including children and adolescents) in both modern and traditional countries protesting, resisting, and rejecting oppressive governmental policies. Along with this, the suppression of justice has been more visibly documented given the use of social media, the internet, and other forms of communication (e.g., Arab Spring, student protests for autonomy in Hong Kong, Black Lives Matters, \#MeToo movement, call for human rights for refugees). These explicit examples of protests for justice and rights within countries, societies, and cultures have contributed to new theories about the relations between individuals and cultural ideologies and values across the globe (Kendi, 2016; Khan-Cullors \& Bandele, 2018).

The negative consequences of experiencing discrimination, victimization, social exclusion, and injustice are extensive and have been documented by researchers using physiological, psychological, sociological, neuroscientific, and economic theories and methodologies (Cooper et al., 2015; Duncan \& Murnane, 2011; Graham, 2006; Neblett \& Roberts, 2013; Rivas-Drake et al., 2014; Ruck et al., 2019; Rutland \& Killen, 2015; Yip, 2014). These negative consequences include stress, anxiety, depression, and social withdrawal (Neblett \& Roberts, 2013; Rivas-Drake et al., 2014). Experiences of discrimination and social exclusion early in development can alter the life course dramatically by obstructing healthy biological, cognitive, social, and moral development. Moreover, children and adolescents are vulnerable populations by virtue of their developmental immaturity as well as their reliance on adults for material and psychological support. Thus, rectifying inequalities and addressing social injustice is an urgent matter if we expect both current and future generations to thrive.

Thus, to summarize, psychological theory and research over the past decade have challenged research traditions that undermine human integrity, view cognition as nonrational, and perpetuate assertions that certain people are inferior solely because of their gender, race, religion, ethnicity, and nationality (along with many other identities). Shifts in guiding frameworks need to be aligned with current research and practice (see Budwig \& Alexander, 2021). In this article, we identify new theoretical perspectives that provide robust findings for several interrelated issues: (a) how children and adolescents conceptualize social justice issues; (b) when individuals view challenging unfair practices as obligatory; and (c) how social injustice negatively impacts child and adolescent development.

Research examining psychological attitudes, judgments, and reasoning about what counts as justice, fairness, and equality and how individuals experience injustice, unfairness, and inequality is necessary for creating change and progress towards the achievement of social justice. This guest-edited issue of Human Development, entitled "Promoting Social Equity, Fairness, and Racial Justice in Development," profiles current theoretical and empirical approaches to studying aspects of human development that have directly addressed racial justice as well as social justice more broadly. To a large extent, the authors have a dual goal in their scholarship: the discovery of new knowledge about the types of psychological attitudes, beliefs, and behaviors that perpetuate inequalities as well as foster social equalities, and a call to action for scholars and experts to investigate the source, cause, and remedies for social injustice in human development. Moreover, these authors are committed to affecting change towards social justice as one of the broader impacts of their scholarship. We turn to four shifts in the field of human development that reflect theoretical changes in psychological research on social and racial justice.

\section{Theoretical Shifts in Psychological Research on Social Justice}

Socialization Theories about Race

Socialization theories have traditionally characterized parent-child relationships as unilateral. Parents modeled 
positive behavior for children, who needed to identify with their parents in order to "become socialized" (see Grusec \& Goodnow, 1994). This viewpoint has changed significantly over the past few decades towards a framework that provides more agency to youth, particularly regarding cognitive, social, and moral development (Flanagan et al., 2016; Rogers et al., 2021, this issue; Smetana, 2011). In the area of social justice, for example, previous research on civic engagement in childhood and adolescence focused on socialization models of intergenerational transmission of political attitudes. From the traditional viewpoint, parents socialized adolescents about societal and political involvement.

As scholars have focused on youth's agency, research has shown the remarkable ways in which children and adolescents assert their autonomy to create societal change. For example, young people have worked to create environmental change, promote gun safety, assert the necessity of freedom for expressions of sexual identity, and call for an elimination of police brutality against Black men and women (Flanagan et al., 2016; Ruck \& Tang, 2019; Russell, 2016). Recent adolescent research on agency and autonomy has also included more participants from historically marginalized as well as non-marginalized backgrounds, which is long overdue (Graham et al., 2009). Examining conditions of oppression has demonstrated the important role that critical consciousness (reflection, motivation, and action) plays for ethnic and racial minority adolescents experiencing discrimination and bias (Diemer et al., 2015). Rejecting group norms that uphold the unfair treatment of others reveals the role of agency for non-marginalized youth despite the cost that often accompanies challenging the status quo. Russell (2016) asserts that it is the responsibility of scholars who conduct research on children and adolescents to be conscious of biases, power, and privilege within developmental science, both for the questions posed by researchers as well as for the goals and methodologies chosen for research.

To advance racial justice, Rogers et al. (2021, this issue) propose a reconceptualization of macro- and micro-levels of development to address racism and how the sociopolitical context of racism is itself a source of socialization, referred to as Anti-Racist Socialization (ARS). Their argument is that developmental research too often focuses on psychological processes at the micro-level of individuals and relationships without fully taking into account macro-level forces, such as the cultural and historical conditions which intricately impact development. One example that reflects this bias is the emphasis that many parents and educators have placed on promoting a colorblind approach to parenting, teaching, and learning (Pahlke et al., 2012). Colorblind socialization was often justified as an egalitarian principle, treating everyone the same. This approach stemmed from the Civil Rights movement and Martin Luther King Jr.'s goal for judging every individual not "by the color of their skin but by the content of their character." Unfortunately, this phrase was mis-interpreted by many parents to mean that race should not be a point of discussion. Silence about race, however, does not help explain why inequalities exist, or how to rectify and challenge unfair treatment towards others. Moreover, a colorblind approach as a socialization strategy only works when there is a level playing field (Alexander, 2012).

What extensive research has demonstrated over the past several decades is that children from different ethnic, racial, religious, and other group memberships do not start on equal footing (Duncan \& Murnane, 2011; Hughes et al., 2006; Sellers et al., 2001). Moreover, discussing the facts of history in any given society is an important part of helping children to understand the larger societal context of disparities, referred to as structural inequalities (Heckman \& Mosso, 2014). Further, research has shown that most ethnic and racial minority parents prepare their children for the world of discrimination, which necessitates explicit conversations about race (Hughes et al., 2006; Rivas-Drake \& Umaña-Taylor, 2019). In contrast, White majority parents often refrain from talking about race, believing these discussions to be too negative or unnecessary (Abaied \& Perry, 2021).

Against this backdrop of research on racial justice and injustice, Rogers et al. (2021, this issue) assert that the interplay between macro- and micro-level contexts are integral to understanding human development due to the structural racism and hierarchies of oppression that have been pervasive throughout human history. Currently, there remains a disparity between the macro-level framework and the preponderance of developmental research that investigates processes at the micro-level of individual development. This disparity applies to research focused on families from ethnic/racial minority, as well as majority backgrounds.

Making their argument, Rogers et al. (2021, this issue) draw on data collected from a study of Black and White parents of young children as part of a larger study on social, behavioral, and physical health among racially and economically diverse Americans (Chae et al., 2021). They demonstrate how parents' socialization about racism varies by context, specifically, the neighborhoods where they live, which reflect different political positions about racial 
injustice. Further, their framework is validated by important and burgeoning areas of research on child and human development, as reflected in this issue.

Importantly, children are acutely aware of these disparities. Emerging research on how children and adolescents think about social mobility and status hierarchies indicates that children and adolescents living in traditional hierarchical societies, for example, recognize the obstacles to social mobility, such as parental concerns about social reputation and status (Grütter et al., in press). Research that views the sociopolitical context of racism as a form of socialization must be incorporated into accounts of individual development in order to ensure that children are equipped to recognize and defy injustices. Research on ethnic-racial identity (ERI) is one aspect of social justice research that has reflected this shift towards greater consideration of child agency and has moved the field from an ethnic-racial majority to minority perspective.

\section{Ethnic-Racial Identity Development}

Identity development has been a foundational area of research in developmental psychology starting with Erikson's (1968) classic book on identity development. Erikson (1968) focused on cycles of identity crises which were framed as universal stages in development. Over the past 30 years, this focus shifted away from a generalized identity development towards ethnic identity development (Phinney, 1990). More recently, however, the field has expanded exponentially with research on how ERI development provides an important mechanism for resilience against experiences of discrimination (Yip, 2014). An expansive body of research has documented ethnic racial identity exploration and development using a range of methodologies, including interview, survey, and daily diary studies (Hughes et al., 2006; Kiang et al., 2006). For example, daily diary assessments with Mexican and Chinese youth revealed that adolescents with a greater regard for their ethnic group displayed greater levels of daily happiness and less daily anxiety over a 2-week study period (Kiang et al., 2006).

Longitudinal research with African American adolescents aged 14-18 years examined relations between perceived racial discrimination and racial identity dimensions (Seaton et al., 2009). Using a multidimensional approach to racial identity, the authors assessed racial centrality, private regard, and public regard, which refer to the extent to which race is a defining characteristic for the individual, how positively the individual feels about their race, and beliefs about others' evaluations of one's own race, respectively (Sellers et al., 2001). The findings in Seaton et al.'s (2009) longitudinal study revealed that perceived discrimination was negatively related to public regard assessed 1 year later. This suggests a potential causal connection between experiences of discrimination and negative views about how the larger society perceives one's own group.

Ethnic and racial identity has been studied extensively by Umaña-Taylor and Rivas-Drake, 2021 (2021, this issue), who assert that past theorizing about ethnic and racial minority children and adolescents took a deficit model approach, identifying the developmental delays and challenges that exist for ethnic and racial minority youth (see also Cabrera \& Leyendecker, 2017, for a similar argument). To expand upon this framework, researchers have taken a risk and resilience approach, identifying both risk factors for minority students such as experiences of discrimination, and also aspects of ERI that provide resilience against experiences of social exclusion (UmañaTaylor et al., 2008). This framework has found empirical support for relations between increased ERI exploration and resolution and the ability to manage stress associated with ethnic and racial discrimination (Rivas-Drake et al., 2014; Umaña-Taylor et al., 2008).

An important goal of this program of research is to enable youth of color to recognize that stress symptoms can result from experiences related to societal and systemic racism rather than from individual deficits (Neblett et al., 2012; Rivas-Drake \& Umaña-Taylor, 2019). Focusing on strengths in ethnic/racial minority youth provides an important alternative to the deficit model that has often guided research questions. A competency approach broadens the understanding of how to ameliorate the negative consequences of social injustice for those who experience it. Moreover, the inclusion of empirical research examining the normative developmental processes and dynamics within ethnic and racial minority families has provided extensive knowledge about ethnic and racial minority child and adolescent development (Hughes et al., 2006; Garcia Coll et al., 1996).

Child development research has also investigated the attitudes, beliefs, and behaviors held by majority White children and adolescents that often perpetuate injustice and unfair treatment of others, including in the context of peer relationships. At the same time, research has also shown that there are contexts in which White adolescents view prejudicial attitudes as wrong, and desire to rectify this type of behavior. Thus, it is essential to document the conditions that contribute to a negative or positive path. Research on social identity from childhood to adulthood 
has shed light on the group dynamics that, if left unchecked, can set in motion a number of attitudes and beliefs that contribute to injustice. Over the past two decades, research on developmental intergroup attitudes, beliefs, and judgments in childhood and adolescence has burgeoned.

\section{Developmental Social Identity and Moral Reasoning}

To increase social justice, it is necessary to change attitudes and biases that perpetuate prejudicial and discriminatory treatment of others. Previously, theories focused on adult attitudes, with the expectation that children were unaware of prejudice. Extensive research has shown that prejudice and bias originate in childhood, however, and evolve through adolescence to adulthood (Levy et al., 2016; Raabe \& Beelmann, 2011). Developmental research on social identity and intergroup bias, which includes ingroup preference and outgroup distrust, takes a group-level approach to prejudice. This is in contrast to previous theorizing which explained prejudice at the individual level, such as attributing it to personality deficits. Similar to theories about socialization and ethnic/racial identity, studying the origins of prejudice and bias has shifted from an individual deficit model to a group-level normative one (Bigler \& Liben, 2007; Burkholder et al., 2019).

A group-level approach recognizes that prejudice and racism are systemic issues and that their mere pervasiveness may be used to legitimize or disregard the unfair treatment of others. This is more likely to occur when groups, societies, and institutions perpetuate negative attitudes about individuals based on their group membership in order to maintain status hierarchies, power, and prestige (Brown \& Hewstone, 2005; Dovidio et al., 2005; Rutland \& Killen, 2015). Prejudice is often defined as an individual's assignment of traits, intentions, interests, and abilities to others based solely on group membership (such as gender, race, ethnicity, or nationality). While individual bias must be addressed, the issue of prejudice is a much broader societal challenge. Developmental social identity theory (Nesdale, 2004, 2008) has demonstrated that normative expectations about others emerge early in childhood and contribute to prejudicial attitudes.

Developmental research on the origins of prejudice has been conducted across a wide range of groups, including groups based on race, gender, ethnicity, religion, immigrant status, and wealth status (socioeconomic background), as well as from an international perspective (Killen et al., 2011). In addition to studies on race and ethnicity (with the majority focusing on African American and US Latinx samples), research has also included Asian (Kiang et al., 2016), LGBT (Horn \& Sinno, 2014; Russell, 2016), wealth status (Arsenio \& Willems, 2017; Burkholder et al., 2021; Mistry \& Elenbaas, 2021), and Jewish and Arab (Brenick et al., 2019) groups in many countries. A multi-group approach to the study of the origins of prejudice is important because individuals are members of more than one group, referred to as intersectionality (Burkholder et al., 2021; Rogers et al., 2015). As an example, understanding race cannot be fully understood without examining socioeconomic status (Mistry et al., 2021). While very little developmental research, to date, has explicitly studied intersectionality, the move to investigate multiple groups is a first step towards considering the implications of individuals being members of more than one group simultaneously. The study of multiple groups provides insight into the factors that generalize across groups, as well as what makes each group unique in terms of its history, experience of prejudice and discrimination, and paths of resilience (Brenick et al., 2019; Kiang et al., 2016; Seaton et al., 2009; Umaña-Taylor \& Rivas-Drake, 2021, this issue).

One of the underlying premises supported by the literature is that group affiliation often leads to ingroup preferences, designed, in part, to enhance ingroup identity. Individuals are then motivated to exclude others perceived to be members of an outgroup, particularly when ingroup members perceive a threat from the outgroup, such as in conditions of limited resources, competition, or potential aggression (Abrams et al., 2005). It has been well documented, however, that perceived "threat" is often a misjudgment and misattribution stemming from a desire to maintain high status and power (see Dovidio et al., 2015, for a review). Further, social exclusion, derogation, discrimination, and prejudice are unfortunate outcomes of perceived threat, group dynamics and the motivation for status (Brown, 2017). Understanding the origins of thinking and reasoning about injustice provides a basis for intervention given that change is most tenable during childhood and adolescence.

Consistent with a social and developmental intergroup perspective, Verkuyten (2021, this issue) asserts that developmental social identity theories need to be better integrated into research on children's biases to fully enhance an understanding of the origins of prejudice. He calls for more research on four issues: (a) children's conceptualizations of group identity, (b) the importance of children's epistemic motivation, (c) the role of processes of normative influence, and (d) the relevance of 
moral reasoning and considerations of fair and just treatment of others. These foci reflect substantive and robust areas of intergroup prejudice in childhood and adolescence.

Verkuyten (2021, this issue) states that group identity is "simultaneously social and individual, public and private." A central part of a social identity is understanding how societal rules, regulations, symbols, and cultural narratives contribute to one's own group identity. This approach shares much with ethnic and racial identity as explored by Umaña-Taylor and Rivas-Drake (2021, this issue) as well as Tai and Pauker (2021, this issue). As well, social identity includes ingroup belonging which sets in motion the dynamics between ingroup preference and outgroup distrust (Nesdale et al., 2017) which bears on the normative processes that underlie prejudicial attitudes.

To examine the role of moral reasoning regarding intergroup research, as called for by Verkuyten (2021, this issue), research has investigated how individuals evaluate the fair (and unfair) treatment of others who are targeted for differential treatment because of their group identity (Killen \& Rutland, 2011). Understanding prejudice involves knowing the contexts in which children give priority to fair treatment of others in contrast to situations in which ingroup bias and outgroup distrust take priority. When groups become focused on self-promotion at the cost of fair treatment of others, challenging group norms becomes very costly, particularly as children enter early adolescence (Mulvey, 2016). The outcome can be exclusion from the group, which threatens one's group identity and affiliative needs (Killen et al., 2015).

Fortunately, even young children desire to rectify racial inequalities (Elenbaas et al., 2020). As an example, in an experimental task, children aged 5-10 years will give more school supplies to children in schools with few resources than those with lots of resources, and even when the group with few resources is a member of a racial outgroup (Elenbaas et al., 2016). Further, children explicitly discuss the rights to protection (safety from harm), provision (entitlements to food and shelter), and participation (decision-making) (Ruck et al., 2017; Toope, 1996). As an illustration, cross-cultural research by Cherney and Shing (2008) with US, Swiss, and Chinese-Malaysian 12-yearold children found that support for self-determination rights (e.g., wanting to have a different religious practice than their parents) was stronger for US and Swiss children than Chinese-Malaysian children. However, within this latter group, children who identified as Buddhist advocated more strongly for self-determination rights than those who identified as Christian (see Kraus et al., in press). These findings provide a starting point for integrating social identity theory and moral reasoning about intergroup attitudes and relationships in childhood. Another area of theory and research that reflects a shift towards social and racial justice and where social identity also plays a central role has been referred to as lay theories and social essentialist beliefs.

\section{Lay Theories and Beliefs about Essentialism}

Lay theory perspectives examine how explanatory frameworks used to explain everyday phenomena ultimately bias attention, behavior, and interpretations of the social world (Cameron et al., 2001; Levy \& Karafantis, 2008). These theories have challenged biological determinism as explanations for racial differences among individuals. As well, social essentialism, which reflects a lay theory about the structure and nature of social groups, has been a particular focus of intergroup researchers in recent decades (Rhodes \& Mandalaywala, 2017). Research shifted the focus from children's biological folk theories (how children classify and conceptualize animals, for example) to the cognitive biases that contribute to children and adults' theories about the "essential" qualities of human social groups. This can include, but is not limited to, beliefs that group members share deep and meaningful properties (i.e., not merely physical, but also psychological and behavioral traits) and that group membership is inherent and stable. For example, holding a lay theory that racial group membership is biologically inherited may appear to be quite rational given that people who share the same race sometimes share physical properties that are, in fact, biologically inherited. Nevertheless, extensive evidence across scientific fields asserts that race and ethnicity reflect social, conventional, and cultural distinctions (Gould, 1981; Graves, 2002; Umaña-Taylor, 2015).

Viewing race as inherited has been associated with the perception of racial outgroup members as more socially distant, increased interracial discomfort, and reduced willingness to engage in interracial friendships (Williams \& Eberhardt, 2008; Tawa, 2016). More promisingly, interracial contact and exposure to racial ambiguity have been shown to buffer the development of a biological lay theory of race (Pauker et al., 2018; Sanchez et al., 2015). A longitudinal study by Pauker et al. (2018) investigated college students' shifts in biological lay theories after moving from the continental United States to Hawai'i. This is the most racially diverse state in the United States and contains a high multiracial population $(22.6 \%)$, and 
a non-White majority. Over a 9-month period, White students' diversity of acquaintances corresponded with a decreased endorsement of a biological lay theory of race, which was further associated with increased egalitarian attitudes and cognitive flexibility. Similarly, Sanchez et al. (2015) found that exposure to racial ambiguity reduced White adults' endorsement of a biological lay theory 2 weeks later, and that this effect was mediated by their conforming to beliefs they presumed racially ambiguous individuals to hold. Thus, investigating the nature and development of lay theories and understanding how they shape social experiences can inform methods aimed to mitigate the emergence of prejudice and bias.

Lay theory research in practice has focused on mindsets, which reflect beliefs that people are capable of changing their traits, abilities, and behavior (i.e., growth mindset, incremental theories) or beliefs that these attributes are stable (i.e., fixed mindset, entity theories) (Dweck, 2006; Levy et al., 2001). Studies have demonstrated that viewing attributes as malleable, and thus, an opportunity for learning and change, can increase motivation for action in the face of obstacles. Children praised for their effort, rather than intelligence, are more likely to believe intelligence could be increased and were therefore more likely to persist and enjoy a task even after failure (Mueller \& Dweck, 1998). Individuals who endorse a fixed mindset tend to make rapid trait-based judgments about others, exhibit confirmatory biases, and have greater expectations for consistent future behavior (Dweck, 2012; Molden et al., 2006). On the contrary, those who endorse a growth mindset tend to consider trait-consistent behavior to be an outcome of the social context and an individual's psychological processes (Pauker et al., 2021). The extent to which one has a dynamic perception of traits may further explain individual differences in the development of stereotyping, prejudice, and willingness to challenge injustices.

Tai and Pauker (2021, this issue) assert that this work should further consider how mindsets may operate differently depending on perspective; they examine how mindsets can motivate collective action towards social justice among racial majority group members, and explore contextual factors that contribute to the development of mindsets over time. Those who view others' attributes as malleable may be motivated to help improve the situation. Indeed, among primarily White 9- to 12-year-olds, Karafantis and Levy (2004) found that increased endorsement of a growth mindset, compared to a fixed mindset, was associated with greater engagement in prosocial behavior, more positive attitudes, desire for contact, and perceived similarity with disadvantaged peers. Moreover, the extent to which one views prejudice itself as being malleable influences their approach to interracial interactions. A recent study found that ethnically diverse children and adolescents who believed that people could change their prejudices were less likely to exhibit interracial anxiety and more likely to engage in interracial friendships (Pauker et al., 2021).

This area of research has more recently considered how diverging mindsets, as well as other lay theories, operate in different contexts. For example, a study with ninth-graders found that students' implicit theories about the potential for change moderated depressive symptoms in high adversity schools but not low adversity schools. In high adversity schools, students who experienced greater peer victimization and believed that personality was fixed exhibited greater depression than those who believed that people were capable of changing (Kaufman et al., 2020). Further, children from lower socioeconomic backgrounds were more likely to be victimized (Tippett \& Wolke, 2014) and believe that personality was fixed (Destin et al., 2019) than those from higher socioeconomic backgrounds. Thus, mindset interventions may be most effective among children and adolescents who are at a greater disadvantage.

While much of this research compares the differences in outcomes between growth and fixed mindsets, Tai and Pauker (2021, this issue) suggest that the same orientation may operate differently across different social groups and that researchers should identity whose attributes are the focus of change. A malleable prejudice mindset among racial majority children may involve beliefs that one's own biases can change, whereas the same mindset among racial minority children may involve beliefs that others' biases can change. In this case, the mechanisms by which mindsets operate may additionally depend on prior knowledge about who is more or less likely to perpetuate prejudice.

Moreover, mindsets have most often been examined in the context of individuals, and less is understood about how they operate in the context of groups. Although it may be beneficial to view an individual's attributes as malleable when applied to groups, this view has the potential to lead to the conclusion that certain groups are disadvantaged due to a lack of motivation or effort, which may trivialize or disregard the influence of structural obstacles. Expanding this focus to consider broader perspectives and contexts will better inform future methods for improving and sustaining positive interracial relations in the long term. 


\section{Conclusions}

This special issue of Human Development is motivated by a renewed focus on racial and social injustice, and recent calls for continuing the momentum towards rectifying inequalities and challenging the status quo. We identified four theoretical shifts in predominant areas of human development that have provided new conceptual frameworks for studying and asserting the importance of social and racial justice. These new conceptualizations provide a robust response to psychological research that has thwarted the goal of understanding and documenting the full social, cognitive, and biological capacities of all individuals.

The issue assembles diverse theoretical perspectives and debates that surround current examinations of bias, prejudice, and discrimination during a time of upmost importance. Opponents of recent social justice movements have deemed its advocates as overly sensitive "social justice warriors," but their criticism that current academic research reflects a liberal bias is inconsistent with the bulk of research historically, as well as the contemporary research literature that has been overtly designed to demonstrate the inferiority and incompetence of individuals based on race, ethnicity, gender, and other group identities. Social and scientific progress can only occur when multiple lenses are focused on fundamental questions about human nature.

As Kendi (2016) has written, forces for social equality and inequality have been at play simultaneously throughout human history. The extensive history of prejudice and bias in psychological research needs to be scrutinized and directly addressed from multiple avenues. Sociologists and educators examine the sociocultural categories of power, status, hierarchy, and privilege from a societal viewpoint (Bonilla-Silva, 2015; Lewis et al., 2019). Psychologists have demonstrated the multiple ways in which social inequalities have detrimental implications for child and adolescent development, and how individuals' attitudes, beliefs, judgments, and reasoning about social equalities and inequalities are directly related to the emergence of fair and equal treatment of others. Human development research can shed light on what we know, what works to change attitudes and behaviors, and what requires further exploration. This issue is specifically focused on new theories and research that aim to demonstrate what factors promote equality and which aspects of human interactions and judgments create obstacles to equality.

Intergroup conflicts that contribute to intentions to derogate others, or perpetuate injustice often are derived from rational interpretations of the world and the competing dynamic between the goals of the group and those of the individual (Verkuyten, 2014). Prejudice and discrimination may seem inevitable, yet the principles of fairness, equality, and equity are also consistently valued by most people, including children. In reframing how we think about individuals and societies, we may also change the way in which we respond to social injustice.

The perspectives presented in this issue propose that human development research would benefit from considering the impact of the broader sociopolitical context in racial socialization. This includes shifting the study of ethnic and racial identity from a narrative of deficit to one of competency and resilience. It also involves examining the complex dynamic between the emergence of group identity and moral concerns that underlie bias. In addition, harnessing explanatory frameworks that view individuals as well as societies as capable of growth will be rewarding. The field of human development must continue to move beyond conceptualizing social justice as a zero-sum game, and from "us" versus "them," by considering how different experiences shape our understanding of justice itself and including these perspectives in rigorous scientific research. The theoretical shifts identified in this article provide new frameworks for conducting research on social and racial justice, leading to new research. This new body of work holds the potential to impact how adolescents, and adults interact, communicate, and work towards social justice, equity, and equality.

\section{Acknowledgements}

The authors thank Nancy Budwig and Judith Smetana and the anonymous reviewers for feedback on the manuscript and extend their gratitude to the contributors of the guest-edited issue for their cutting-edge research on fundamentally important and timely topics in human development.

\section{Statement of Ethics}

No ethical approval was required for the preparation of the manuscript, as no human or animal subjects were used.

\section{Conflict of Interest Statement}

The authors have no conflicts of interest to declare. 


\section{Funding Sources}

The first author was supported, in part, by funding from the National Science Foundation, BCS 1728918, and the National Institutes of Health, R01HD093698.

\section{Author Contributions}

Melanie Killen, Kathryn M. Yee, and Martin D. Ruck each contributed to the formulation and writing of the paper.

\section{References}

Abaied, J. L., \& Perry, S. P. (2021). Socialization of racial ideology by white parents. Cultural $D i$ versity and Ethnic Minority Psychology, 27(3), 431-440.

Abrams, D., Hogg, M., \& Marques, J. (2005). A social psychological framework for understanding social inclusion and exclusion. In D. Abrams, M. A. Hogg, \& J. M. Marques (Eds.), The social psychology of inclusion and exclusion (pp. 1-24). Psychology Press.

Alexander, M. (2012). The new Jim Crow: Mass incarceration in the age of color blindness. The New Press.

Anderson, E. S. (1999). What is the point of equality? Ethics, 109(2), 287-337.

Appiah, K. A. (2001). Liberalism, individuality, and identity. Critical Inquiry, 27(2), 305-332.

Appiah, K. A. (2005). The ethics of identity. Princeton University Press.

Arsenio, W. F., \& Willems, C. (2017). Adolescents' conceptions of national wealth distribution: Connections with perceived societal fairness and academic plans. Developmental Psychology, 53(3), 463-474.

Bigler, R. S., \& Liben, L. S. (2007). Developmental intergroup theory: Explaining and reducing children's social stereotyping and prejudice. Current Directions in Psychological Science, 16(3), 162-166.

Bonilla-Silva, E. (1997). Rethinking racism: Towards a structural interpretation. American Sociological Review, 62, 465-480.

Brenick, A., Lawrence, S. E., Carvalheiro, D., \& Berger, R. (2019). Teaching tolerance or acting tolerant? Evaluating skills- and contactbased prejudice reduction interventions among Palestinian-Israeli and Jewish-Israeli youth. Journal of School Psychology, 75, 8-26.

Brown, C. S. (2017). Discrimination in childhood and adolescence: A developmental intergroup approach. Routledge.

Brown, C. S., Mistry, R. S., \& Yip, T. (2019). Moving from the margins to the mainstream: Equity and justice as key considerations for developmental science. Child Development Perspectives, 13(4), 235-240.

Brown, R., \& Hewstone, M. (2005). An integrative theory of intergroup contact. In M. P. Zanna (Ed.), Advances in experimental social psychology (Vol. 37, pp. 255-343). Elsevier Academic Press.

Budwig, N., \& Alexander, A. J. (2021). Exploring the conceptual frameworks guiding developmental research and practice in higher education: Some challenges for transdisciplinary work. Human Development, 65, 1-18.
Burkholder, A. R., D'Esterre, A. P., \& Killen, M. (2019). Intergroup relationships, context, and prejudice in childhood. In H. E. Fitzgerald, D. J. Johnson, D. B. Qin, F. A. Villarruel, \& J. Norder (Eds.), Handbook of children and prejudice: Integrating research, practice, and poli$c y$ (pp. 259-278). Springer International Publishing.

Burkholder, A. R., Elenbaas, L., \& Killen, M. (2021). Giving priority to race or wealth in peer group contexts involving social inclusion. Developmental Psychology, 57(5), 651-661.

Cabrera N., \& Leyendecker B. (Eds.) (2017). Handbook on positive development of minority children and youth. Springer Science + Business Media.

Cameron, J. A., Alvarez, J. M., Ruble, D. N., \& Fuligni, A. J. (2001). Children's lay theories about ingroups and outgroups: Reconceptualizing research on prejudice. Personality and Social Psychology Review, 5(2), 118-128.

Chae, D. H., Yip, T., Martz, C. D., Chung, K., Richeson, J. A., Hajat, A., Curtis, D. S., Rogers, L. O., \& LaVeist, T. A. (2021). Vicarious racism and vigilance during the COVID-19 pandemic: Mental health implications among Asian and Black Americans. Public Health Reports, 136(4), 508-517.

Cherney, I. D., \& Shing, Y. L. (2008). Children's nurturance and self-determination rights: A cross-cultural perspective. Journal of Social Issues, 64(4), 835-856.

Clark, K. B., \& Clark, M. P. (1947). Racial identification and preference among negro children. In T. M. Newcomb \& E. L. Hartley (Eds.), Readings in social psychology (pp. 169178). Holt, Rinehart, \& Winston.

Cooper, S. M., Smalls-Glover, C., Metzger, I., \& Griffin, C. (2015). African American fathers' racial socialization patterns: Associations with racial identity beliefs and discrimination experiences. Family Relations, 64(2), 278290.

Deaux, K. (2006). A nation of immigrants: Living our legacy. Journal of Social Issues, 62(3), 633651.

Deaux, K., \& Major, B. (1987). Putting gender into context: An interactive model of genderrelated behavior. Psychological Review, 94(3), 369-389.

Destin, M., Hanselman, P., Buontempo, J., Tipton, E., \& Yeager, D. S. (2019). Do student mindsets differ by socioeconomic status and explain disparities in academic achievement in the United States? AERA Open, 5(3), 233285841985770
Diemer, M. A., McWhirter, E. H., Ozer, E. J., \& Rapa, L. J. (2015). Advances in the conceptualization and measurement of critical consciousness. The Urban Review, 47(5), 809823.

Dovidio, J. F., Gaertner, S. L., Hodson, G., Houlette, M. A., \& Johnson, K. M. (2005). Social inclusion and exclusion: Recategorization and the perception of intergroup boundaries. In D. Abrams, M. A. Hogg, \& J. M. Marques (Eds.), The social psychology of inclusion and exclusion (pp. 245-264). Psychology Press.

Dovidio, J. F., Gaertner, S. L., \& Saguy, T. (2015). Color-blindness and commonality: Included but invisible? American Behavioral Scientist, 59(11), 1518-1538.

Duncan, G. J., \& Murnane, R. J. (Eds.). (2011) Whither opportunity? Rising inequality, schools, and children's life chances. Russell Sage Foundation.

Dweck, C. S. (2006). Mindset: The new psychology of success. Random House.

Dweck, C. S. (2012). Mindsets and human nature: Promoting change in the Middle East, the schoolyard, the racial divide, and willpower. American Psychologist, 67(8), 614-622.

Elenbaas, L., Rizzo, M. T., Cooley, S., \& Killen, M. (2016). Rectifying social inequalities in a resource allocation task. Cognition, 155, 176187.

Elenbaas, L., Rizzo, M. T., \& Killen, M. (2020). A developmental-science perspective on social inequality. Current Directions in Psychological Science, 29(6), 610-616.

Erikson, E. H. (1968). Identity: Youth and crisis. Norton \& Co.

Flanagan, C. A., Byington, R., Gallay, E., \& Sambo, A. (2016). Social justice and the environmental commons. In S. S. Horn, M. D. Ruck, \& L. S. Liben (Eds.), Advances in Child Development and Behavior: Vol. 51. Equity and justice in developmental science: Implications for young people, families, and communities (pp. 203-230). Elsevier.

Fourie, C., Schuppert, F., \& Wallimann-Helmer, I. (2015). Social equality: On what it means to be equals. Oxford University Press.

Garcia Coll, C., Lamberty, G., Jenkins, R., McAdoo, H. P., Crnic, K., Wasik, B. H., \& Garcia, H. V. (1996). An integrative model for the study of developmental competencies in minority children. Child Development, 67(5), 1891-1914. 
Gönültaş, S., \& Mulvey, K. L. (2019). Social-developmental perspective on intergroup attitudes towards immigrants and refugees in childhood and adolescence: A roadmap from theory to practice for an inclusive society. $\mathrm{Hu}$ man Development, 63(2), 90-111.

Gould, S. J. (1981). The mismeasure of man. W. W. Norton \& Company.

Graham, S. (2006). Peer victimization in school: Exploring the ethnic context. Current Directions in Psychological Science, 15(6), 317-321.

Graham, S., Taylor, A. Z., \& Ho, A. Y. (2009). Race and ethnicity in peer relations research. In K. H. Rubin, W. M. Bukowski, \& B. Laursen (Eds.), Handbook of peer interactions, relationships, and groups (pp. 394-413). The Guilford Press.

Graves, J. (2002). The emperor's new clothes. Biological theories of race at the millennium. Rutgers University Press.

Grusec, J. E., \& Goodnow, J. J. (1994). Impact of parental discipline methods on the child's internalization of values: A reconceptualization of current points of view. Developmental Psychology, 30(1), 4-19.

Grütter, J., Dhakal, S., \& Killen, M. (in press). Adolescents' own and parental expectations for cross-group friendship in the context of social inequalities. Journal of Social Issues.

Haidt, J., \& Bjorklund, F. (2008). Social intuitionists answer six questions about moral psychology. In W. Sinnott-Armstrong (Ed.), Moral psychology: Vol. 2. The cognitive science of morality: Intuition and diversity (pp. 181217). MIT Press.

Heckman, J. J., \& Mosso, S. (2014). The economics of human development and social mobility. Annual Review of Economics, 6(1), 689733.

Helwig, C. C., Ruck, M. D., \& Peterson-Badali, M. (2014). Rights, civil liberties, and democracy. In M. Killen \& J. G. Smetana (Eds.), Handbook of moral development (pp. 46-69). Psychology Press.

Herrnstein, R. J. (1994). The bell curve: Intelligence and class structure in American life. Free Press.

Horn, S. S., \& Sinno, S. M. (2014). Gender, sexual orientation, and discrimination based on gender and sexual orientation. In M. Killen \& J. G. Smetana (Eds.), Handbook of moral development (2nd ed., pp. 317-339). Psychology Press.

Hughes, D., Smith, E. P., Stevenson, H. C., Rodriguez, J., Johnson, D. J., \& Spicer, P. (2006). Parents' ethnic-racial socialization practices: A review of research and directions for future study. Developmental Psychology, 42(5), 747770.

Jensen, A. (1998). The gfactor: The science of mental ability. Greenwood Publishing Group.

Jost, J. T., \& Kay, A. C. (2010). Social justice: History, theory, and research. In S. T. Fiske, D. T. Gilbert, \& G. Lindzey (Eds.), Handbook of social psychology (pp. 1122-1165). John Wiley $\&$ Sons.
Karafantis, D. M., \& Levy, S. R. (2004). The role of children's lay theories about the malleability of human attributes in beliefs about and volunteering for disadvantaged groups. Child Development, 75(1), 236-250.

Kaufman, T. M. L., Lee, H. Y., Benner, A. D., \& Yeager, D. S. (2020). How school contexts shape the relations among adolescents' beliefs, peer victimization, and depressive symptoms. Journal of Research on Adolescence, 30(3), 769-786.

Kendi, I. X. (2016). Stamped from the beginning. Avalon Publishing Group.

Kendi, I. X. (2019). How to be an antiracist. One World.

Khan-Cullors, P. \& Bandele, A. (2018). When they call you a terrorist: A Black Lives Matter Memoir. St. Martin's Press.

Kiang, L., Tseng, V., \& Yip, T. (2016). Placing Asian American child development within historical context. Child Development, 87(4), 995-1013.

Kiang, L., Yip, T., Gonzales-Backen, M., Witkow, M., \& Fuligni, A. J. (2006). Ethnic identity and the daily psychological well-being of adolescents from Mexican and Chinese backgrounds. Child Development, 77(5), 13381350 .

Killen, M., \& Dahl, A. (2021). Moral reasoning enables developmental and societal change. Perspectives on Psychological Science, 1-17.

Killen, M., Hitti, A., Cooley, S., \& Elenbaas, L. (2015). Morality, development, and culture. In M. J. Gelfand, C. Chiu, \& Y. Hong (Eds.), Handbook of advances in culture and psychology (pp. 161-220). Oxford University Press.

Killen, M. \& Rutland, A. (2011). Children and social exclusion: Morality, prejudice, and group identity. Wiley-Blackwell.

Killen, M., Rutland, A., \& Ruck, M. D. (2011). Promoting equity, tolerance, and justice in childhood and commentaries. Social Policy Report, 25(4), 1-33.

King, M. L. (1986). I have a dream: Writings and speeches that changed the world (J. M. Washington, Ed.). Harper Collins.

Kraus, J., Ruck, M. D., Peterson-Badali, M., \& Emuke, C. (in press). Being and becoming: Centering the morality of social responsibility through children's right to participate in society. In M. Killen \& J. G. Smetana (Eds.), The handbook of moral development (3rd ed.). Psychology Press.

Levy, S. R., \& Karafantis, D. M. (2008). Lay theories and intergroup relations. In S. M. Quintana \& C. McKown (Eds.), Handbook of race, racism, and the developing child. John Wiley \& Sons.

Levy, S. R., Lytle, A., Shin, J. E., \& Hughes, J. M. (2016). Understanding and reducing racial and ethnic prejudice among children and adolescents. In T. D. Nelson (Ed.), Handbook of prejudice, stereotyping, and discrimination (pp. 471-500). Psychology Press.
Levy, S. R., Plaks, J. E., Hong, Y., Chiu, C., \& Dweck, C. S. (2001). Static versus dynamic theories and the perception of groups: Different routes to different destinations. Personality and Social Psychology Review, 5(2), 156168.

Lewis, A., Hagerman, M., \& Forman, T. (2019). The sociology of race \& racism: Key concepts, contributions \& debates. Equity \& Excellence in Education, 52(1), 29-46.

Mistry, R. S., \& Elenbaas, L. (2021). It's all in the family: Parents' economic worries and youth's perceptions of financial stress and educational outcomes. Journal of Youth and Adolescence, 50(4), 724-738.

Mistry, R. S., Elenbaas, L., Griffin, K. M., Nenadal, L., \& Yassine, A. (2021). Advancing developmental intergroup perspectives on social class. Child Development Perspectives, 1-7.

Molden, D. C., Plaks, J. E., \& Dweck, C. S. (2006). "Meaningful" social inferences: Effects of implicit theories on inferential processes. Journal of Experimental Social Psychology, 42(6), 738-752.

Mueller, C. M., \& Dweck, C. S. (1998). Praise for intelligence can undermine children's motivation and performance. Journal of Personality and Social Psychology, 75(1), 33-52.

Mulvey, K. L. (2016). Children's reasoning about social exclusion: Balancing many factors. Child Development Perspectives, 10(1), 22-27.

Neblett, E. W. Jr., Rivas-Drake, D., \& UmañaTaylor, A. J. (2012). The promise of racial and ethnic protective factors in promoting ethnic minority youth development. Child Development Perspectives, 6(3), 295-303.

Neblett, E. W. Jr., \& Roberts, S. O. (2013). Racial identity and autonomic responses to racial discrimination. Psychophysiology, 50(10), 943-953.

Nesdale, D. (2004). Social identity processes and children's ethnic prejudice. In M. Bennett \& F. Sani (Eds.), The development of the social self (pp. 219-246). Taylor \& Francis.

Nesdale, D. (2008). Peer group rejection and children's intergroup prejudice. In S. R. Levy \& M. Killen (Eds.), Intergroup attitudes and relations in childhood through adulthood (pp. 32-46). Oxford University Press.

Nesdale, D., Brown, C. S., \& Rutland, A. (2017). Researching children's social groups. In A. Rutland, D. Nesdale, \& C. S. Brown (Eds.), The Wiley handbook of group processes in children and adolescents (pp. 67-97). WileyBlackwell.

Nishina, A., \& Witkow, M. R. (2020). Why developmental researchers should care about biracial, multiracial, and multiethnic youth. Child Development Perspectives, 14(1), 21-27.

Nussbaum, M. (1999). Sex and social justice. Oxford University Press.

Nussbaum, M. (2001). Upheavals of thought: The intelligence of emotions. Cambridge University Press. 
Oyserman, D., Coon, H. M., \& Kemmelmeier, M. (2002). Rethinking individualism and collectivism: Evaluation of theoretical assumptions and meta-analyses. Psychological Bulletin, 128(1), 3-72.

Pahlke, E., Bigler, R. S., \& Suizzo, M.-A. (2012). Relations between colorblind socialization and children's racial bias: Evidence from European American mothers and their preschool children. Child Development, 83(4), 1164-1179.

Pauker, K., Apfelbaum, E. P., Dweck, C. S., \& Eberhardt, J. L. (2021). Believing prejudice can change increases children's interest in interracial interactions [Unpublished manuscript]. Department of Psychology, University of Hawai'i at Manoa.

Pauker, K., Carpinella, C., Meyers, C., Young, D. M., \& Sanchez, D. T. (2018). The role of diversity exposure in Whites' reduction of race essentialism over time. Social Psychological and Personality Science, 9(8), 944-952.

Petersen, A., Koller, S. H., Motti-Stefanidi, F., \& Verma, S. (2016). Global equity and justice issues for young people during the first three decades of life. In S. S. Horn, M. D. Ruck, \& L. S. Liben (Eds.), Advances in Child Development and Behavior: Vol.51. Equity and justice in developmental science: Implications for young people, families, and communities (pp. 289-320). Elsevier.

Phinney, J. S. (1990). Ethnic identify in adolescents and adults: Review of the research. Psychological Bulletin, 108(3), 499-514.

Raabe, T., \& Beelmann, A. (2011). Development of ethnic, racial, and national prejudice in childhood and adolescence: A multinational meta-analysis of age differences. Child Development, 82(6), 1715-1737.

Raeff, C. (2010). Independence and interdependence in children's developmental experiences. Child Development Perspectives, 4(1), 31-36.

Rawls, J. (1971). A theory of justice. Harvard University Press.

Rhodes, M., \& Mandalaywala, T. M. (2017). The development and developmental consequences of social essentialism. Wiley Interdisciplinary Reviews: Cognitive Science, 8(4), e1437.

Rivas-Drake, D., Seaton, E. K., Markstrom, C., Quintana, S., Syed, M., Lee, R. M., Schwartz, S. J., Umaña-Taylor, A. J., French, S., \& Yip, T. (2014). Ethnic and racial identity in adolescence: Implications for psychosocial, academic, and health outcomes. Child Development, 85(1), 40-57.

Rivas-Drake, D., \& Umaña-Taylor, A. J. (2019). Below the surface: Talking with teens about race, ethnicity and identity. Princeton University Press.

Roberts, S. O., \& Rizzo, M. T. (2020). The psychology of American racism. American Psychologist.

Rogers, L. O., Niwa, E. Y., Chung, K., Yip, T., \& Chae, D. (2021). M(ai)cro: Centering the macrosystem in human development. Human Development, 65.
Rogers, L. O., Scott, M. A., \& Way, N. (2015). Racial and gender identity among Black adolescent males: An intersectionality perspective. Child Development, 86(2), 407-424.

Ruck, M. D., Mistry, R. S., \& Flanagan, C. A. (2019). Children's and adolescents' understanding and experiences of economic inequality: An introduction to the special section. Developmental Psychology, 55(3), 449-456.

Ruck, M. D., Peterson-Badali, M., \& Helwig, C. C. (2014). Children's perspectives on nurturance and self-determination rights: Implications for development and well-being. In A. Ben-Arieh, F. Casas, I. Frønes, \& J. E. Korbin (Eds.), Handbook of children's well-being: Theories, methods, and policies in global perspectives (pp. 2537-2560). Springer.

Ruck, M. D., \& Tang, J. (2019). Making children's rights and participation central in children's political development. [Invited peer commentary on the article "Toward a developmental science of politics". by M. M. Patterson, R. S. Bigler, E. Pahlke, C. S. Brown, A. R. Hayes, M. C. Ramirez, and A. A. Nelson]. Monograph Matters. https://monographmatters.srcd.org/2019/09/10/commentary-ruckandtang-84-3/

Russell, S. T. (2016). Social justice, research, and adolescence. Journal of Research on Adolescence, 26(1), 4-15.

Rutland, A., \& Killen, M. (2015). A developmental science approach to reducing prejudice and social exclusion: Intergroup processes, socialcognitive development, and moral reasoning. Social Issues and Policy Review, 9(1), 121-154.

Saini, A. (2017). Inferior: How science got women wrong - And the new research that's rewriting the story. Beacon Press.

Sanchez, D. T., Young, D. M., \& Pauker, K. (2015). Exposure to racial ambiguity influences lay theories of race. Social Psychological and Personality Science, 6(4), 382-390.

Seaton, E. K., Yip, T., \& Sellers, R. M. (2009). A longitudinal examination of racial identity and racial discrimination among African American adolescents. Child Development, 80(2), 406-417.

Sellers, R., Morgan, L., \& Brown, T. (2001). A multidimensional approach to racial identity: Implications for African American children. In A. M. Neal-Barnett, J. M. Contreras, \& K. A. Kerns (Eds.), Forging links: African American children clinical developmental perspectives (pp. 23-56). Praeger.

Sen, A. (2009). The idea of justice. Belknap Press of Harvard University Press.

Shweder, R. A., Mahaptra, M., \& Miller, J. G. (1987). Culture and moral development. In J. Kagan \& S. Lamb (Eds.), The emergence of morality in young children (pp. 1-83). University of Chicago Press.

Smetana, J. G. (2011). Adolescents, families, and social development: How teens construct their worlds. Wiley-Blackwell.
Tai, C. \& Pauker, K. (2021). Growing racial resilience: The impact of mindsets on the development of prejudice. Human Development, 65.

Tawa, J. (2016). Belief in race as biological: Early life influences, intergroup outcomes, and the process of "unlearning." Race and Social Problems, 8(3), 244-255.

Tippett, N., \& Wolke, D. (2014). Socioeconomic status and bullying: A meta-analysis. American Journal of Public Health, 104(6), e48-e59.

Toope, S. J. (1996). The convention on the rights of the child: Implications for Canada. In M. Freeman (Ed.), Children's rights: A comparative perspective. Dartmouth Publishing Company.

Triandis, H. C. (1995). Individualism and collectivism: New directions in social psychology. Routledge.

Turiel, E. (2002). The culture of morality: Social development, context, and conflict. Cambridge University Press.

Turiel, E., Chung, E., \& Carr, J. A. (2016). Struggles for equal rights and social justice as unrepresented and represented in psychological research. In S. S. Horn, M. D. Ruck, \& L. S. Liben (Eds.), Advances in child development and behavior: Vol. 50. Equity and justice in developmental science: Theoretical and methodological issues (pp. 1-29). Elsevier.

Umaña-Taylor, A.J. (2015). Ethnic identity research: How far have we come? In C.E. Santos, \& A. J. Umaña-Taylor (Eds.), Studying ethnic identity: Methodological and conceptual approaches across disciplines (pp. 11-26). American Psychological Association.

Umaña-Taylor, A. J. \& Rivas-Drake, D. (2021). Ethnic-racial identity and adolescents' positive development in the context of ethnic-racial marginalization: Unpacking risk and resilience. Human Development, 65.

Umaña-Taylor, A. J., Vargas-Chanes, D., Garcia, C. D., \& Gonzales-Backen, M. (2008). A longitudinal examination of Latino adolescents' ethnic identity, coping with discrimination, and self-esteem. The Journal of Early Adolescence, 28(1), 16-50.

Verkuyten, M. (2014). Identity and cultural diversity: What social psychology can teach us. Routledge.

Verkuyten, M. (2021). Group identity and ingroup bias: The social identity approach. $\mathrm{Hu}$ man Development, 65.

Wainryb, C., \& Recchia, H. (2014). Moral lives across cultures: Heterogeneity and conflict. In M. Killen \& J. G. Smetana (Eds.), Handbook of moral development (pp. 259-278). Psychology Press.

Williams, M. J., \& Eberhardt, J. L. (2008). Biological conceptions of race and the motivation to cross racial boundaries. Journal of Personality and Social Psychology, 94(6), 1033-1047.

Yip, T. (2014). Ethnic identity in everyday life: The influence of identity development status. Child Development, 85(1), 205-219. 